\title{
Bladder Neck Reconstruction in Radical Prostatectomy: What we still can learn and improve?
}

The May-June 2015 issue of the International Braz J Urol presents original contributions with a lot of interesting papers in different fields: Urinary tract infection, Penile Prosthesis, Erectile Disfunction, Neuro-urology, Penile Cancer, Prostate Cancer, Renal Cancer, Neprholithiasis, Pediatric Urology and basic research. The papers come from many different countries such as Brazil, USA, Turkey, Iran, Nigeria, France, German, Italy, Indian, Russia, Sweden, Spain, Colombia and as usual the editor 's comment highlights some papers.

In this issue we had 5 papers about prostate cancer: Two about diagnosis (prostate biopsy), one about brachyterapy, one about surgical technique and one about robotic prostatectomy and we decided to comment about the point of technique in prostate cancer. Doctor Tolkach and collegues, from Sweden and Russia on page 50 an interesting study about a new technique of bladder neck reconstruction in open radical prostatectomy. The authors evaluated the functional outcomes of radical prostatectomy in terms of urinary continence in patients with prostate cancer, in whom a new method of bladder neck reconstruction (BNR) with a deep dorsal stitch was applied, and also to find the potential underlying mechanisms for the efficacy of the BNR using anatomical models. Open radical retropubic prostatectomy was performed in 84 patients: 39 patients with a new BNR method used to improve continence and control group of 45 patients with standard "tennis racket" BNR. Median follow-up was 14 months in control group and 12 months in study group. Continence recovery was accessed early postoperatively and every 3 months thereafter. Anatomical study was performed on 2 male fresh cadavers reproducing two different BNR techniques to clarify any underlying continence related mechanisms. Patients with new BNR achieved full continence significantly faster. The authors concluded that the safety and efficacy of the new method of bladder neck reconstruction using a deep dorsal stitch was documented by this study. An improved early continence was proven, compared to the standard technique of bladder neck reconstruction using a "tennis racket". The possible explanation for this clinical effect could be the presence of proximal passive closure mechanism at the level of bladder neck, which probably promoted continence until the distal sphincter complex could take over.

The preservation of potency and urinary continence is the most important objective of the radical prostatectomy. One of the great merits of the advent of radical prostatectomy by robotics is the better visualization of the structures during surgery, in contrast to open surgery, especially the ability to confirm the structure of the prostatic fascia. This enables the surgeon to select the best layer among the inter-fascial, intra-fascial or extra-fascial when a nerve-sparing procedure is carried out (1-3). Robotic surgery is still more expensive (on average 1.595 euros more expensive than the pure 


\section{EDITORIAL}

laparoscopic technique), which in turn is more costly than the traditional open procedures the open radical prostatectomy is still the first choice for surgical treatment of prostate cancer in some places specially in developed countries (4) and new techniques to improve the results of the open radical prostatectomy are very useful for many urological surgeons.

\section{REFERENCES}

1. Zorn KC, Gofrit ON, Orvieto MA, Mikhail AA, Zagaja GP, Shalav AL. Robotic-assisted laparoscopic prostatectomy: functional and pathological outcomes with interfascial nerve preservation. Eur Urol. 2007:51:755-62.

2. Rassweiler J. Intrafascial nerve-sparing laparoscopic radical prostatectomy: do we really preserve relevant nervefibers? Eur Urol. 2006;49:955-7.

3. Walz J, Burnett AL, Costello AJ, Eastham JA, Graefen M, Guillonneau B, Menon M, Montorsi F, Myers RP, Rocco B, Villers A. A critical analysis of the current knowledge of surgical anatomy related to optimization of cancer control and preservation of continence and erection in candidates for radical prostatectomy. Eur Urol. 2010;57:179-92.

4. Close A, Robertson C, Rushton S, Shirley M, Vale L, Ramsay C, Pickard R. Comparative cost-effectiveness of robot-assisted and standard laparoscopic prostatectomy for treatment of men with localized prostate cancer: a health technology assessment from the perspective of the UK National Health Service. Eur Urol. 2013;64:361-9.

Luciano A. Favorito, MD, PhD

Professor Associado da Unidade de Pesquisa Urogenital da Universidade do Estado do Rio de Janeiro

Editor Associado da International Braz J Urol 